\title{
Smoking and drinking habits of women in subsequent pregnancies after specific advice about the dangers of these exposures during pregnancy
}

\author{
H J Odendaal, ${ }^{1}$ MB ChB, MMed, FCOG (SA), MD, FRCOG; L T Brink, ${ }^{1}$ MSc; D G Nel, ${ }^{2}$ PhD; E Carstens, ${ }^{1}$ RN; M de Jager, ${ }^{1}$ RN; \\ M Potter, ${ }^{1}$ RN; C du Plessis, ${ }^{1}$ RN; C A Groenewald, ${ }^{1}$ MB ChB, MMed, FCOG (SA), MCom \\ ${ }^{1}$ Department of Obstetrics and Gynaecology, Faculty of Medicine and Health Sciences, Stellenbosch University, Cape Town, South Africa \\ ${ }^{2}$ Department of Statistics and Actuarial Science, Faculty of Economic and Management Sciences, Stellenbosch University, Stellenbosch, South Africa
}

Corresponding author: H J Odendaal (hjo@sun.ac.za)

\begin{abstract}
Background. Although women are informed about the dangers of drinking and smoking during pregnancy when they book for antenatal care, it is uncertain whether this advice is accepted, or whether attempts are made to apply it in subsequent pregnancies.

Objectives. To assess how pregnant women respond to the advice to refrain from smoking and drinking during pregnancy in subsequent pregnancies.

Methods. Research staff were trained to obtain accurate prospective information on smoking and drinking during pregnancy in a prospective study, using well-standardised methods. Care was taken to inform participants about the dangers of smoking and drinking during pregnancy. They were also given pamphlets on these dangers in their own language and a list of telephone numbers where they could find help to quit should they need it. This information was repeated at subsequent study visits (ranging from 1 to 3 , depending on the gestational age at which they enrolled). Gestational age was determined by early ultrasound. $Z$-scores of birthweight for gestational age were determined according to the INTERGROWTH-21st study. Pregnancy outcomes of women who enrolled twice $(n=888)$ or three times $(n=77)$ in the Safe Passage Study were compared with those of women in the first enrolment $(n=889)$.

Results. The proportion of drinkers did not change significantly $(p=0.058)$ from the first to the second and third enrolments $(63.8 \%, 59.0 \%$ and $54.6 \%$, respectively). A similar trend was found for smokers $(73.3 \%, 72.2 \%$ and $68.4 \%$, respectively). Cannabis use was reported by $15.1 \%, 9.7 \%$ and $12.0 \%(p<0.005)$ of women, respectively, and use of methamphetamine by $10.1 \%, 6.6 \%$ and $12.7 \%(p<0.005)$. There was an increase in the rate of preterm births from $15.5 \%$ to $17.5 \%$ and $24.7 \%$, respectively, but the increase was not significant. Although mean birthweight was lower in the third enrolment compared with the second, the difference was not significant. The $z$-score of birthweight for gestational age was significantly lower in the second enrolment compared with the first.

Conclusions. Detailed information on the adverse effects of smoking and drinking during pregnancy was not effective in the population studied. Other methods to reduce or stop these toxic exposures should therefore be investigated. A short inter-pregnancy interval, as demonstrated by three enrolments in 7.5 years, is associated with preterm labour and fetal growth restriction, and is probably indicative of the role played by confounders such as poor socioeconomic conditions and drug exposure during pregnancy.
\end{abstract}

S Afr Med J 2020;110(11):1100-1104. https://doi.org/10.7196/SAMJ.2020.v110i11.14667

Globally $72.5 \%$ of pregnant women are daily smokers, of whom $13.5 \%$ smoke heavily. ${ }^{[1]}$ Cigarette smoking and excessive maternal drinking during pregnancy are associated with increased numbers of stillbirths and sudden unexpected deaths. ${ }^{[2,3]}$ In addition, environmental exposure to cigarette smoke is associated with increased numbers of stillbirths and congenital abnormalities, and lower birthweights. ${ }^{[4]}$ Maternal alcohol intake prior to and during pregnancy is also associated with increased numbers of stillbirths and an increase in preterm labour and babies with lower birthweights. ${ }^{[5,6]}$

\section{Objectives}

It is therefore essential to do as much as possible to reduce the risk of exposure to cigarette smoke and alcohol during pregnancy. During the Safe Passage Study (SPS) by the PASS (Perinatal Alcohol, SIDS, Stillbirth) Network, pregnant women were recruited at an antenatal clinic in the community where women at low risk for complications of pregnancy book for antenatal care. ${ }^{[7]}$ At enrolment in the study, the utmost care was taken to advise all participants about the adverse effects of smoking and/or drinking during pregnancy. As enrolment in the study extended over 7.5 years, many participants were recruited again during their next or even a subsequent pregnancy. Comparison of smoking and drinking habits between pregnancies could give an indication of the effectiveness of the information about the adverse effects of smoking and drinking provided during previous pregnancies. Smoking and drinking patterns during the first enrolment in the study were therefore compared with those during the second and third enrolments of the same participants.

\section{Methods}

At recruitment, the purpose of the study and the need for informed consent were carefully explained to potential participants. Each participant received a signed copy of the consent form in Afrikaans or English (the two languages of the study community).

Research staff were specifically trained in the study procedures prior to initiation of the study, and throughout its course. Care was taken to inform participants about the dangers of smoking and drinking during pregnancy. They were also given pamphlets in their own language on these topics and a list of telephone numbers 
where they could find help to quit should they need it. This information was repeated at subsequent study visits (ranging from 1 to 3 , depending on the gestational age at which they enrolled) and for all subsequent pregnancies.

Posters on smoking and drinking were displayed in the waiting room where participants waited before the study assessments. The same pamphlets were also placed on the notice boards of the assessment rooms. Information on the dangers of smoking was repeated by the research midwives at subsequent visits. Women with high Edinburgh depression scores, or social, drinking or drug-related problems, were referred to the social worker of the study, who advised further referrals to other departments, such as psychiatry, if necessary.

After completion of the study, the first study enrolment was compared with the second enrolment and a combination of the third and fourth (only one participant) visits. The inter-pregnancy intervals between the different enrolments were derived from the differences in dates of birth between enrolments.

Socioeconomic conditions, smoking and drinking patterns, neonatal biometry and the outcomes of pregnancy were then compared among the three enrolments.

Data were entered in Excel 365 (Microsoft Corp., USA) and exported to Statistica version 13 (TIBCO Software Inc., USA). Descriptive statistics were used to describe continuous variables, which were compared between groups with analysis of variance. The $\chi^{2}$ test determined significance in categorical data. Bonferroni or least significant difference multiple comparisons identified significant differences between the means. Spearman correlations measured correlations between repetitions of several response variables. Data with outliers were Winsorised by bringing the largest outliers and extremes closer to either the maximum or the minimum within $10 \%$ of the maximum or minimum of the data that were not outliers or extremes.

Permission to conduct this study was obtained from the Health Research Ethics Committee of Stellenbosch University (ref. no. N06/10/210) and the Western Cape Department of Health.

\section{Results}

After exclusions of withdrawals and twin pregnancies from the 7060 pregnant women recruited in the SPS study, 5046 women were enrolled in the study only once and 1854 women two to four times.
There were 889 in the first enrolment, 888 (one woman was lost to follow-up) in the second and 77 in the third. The mean inter-pregnancy interval for women who were included in the study twice was 1251 days. For women included three times, the mean intervals between the first two and last two pregnancies were 932 and 899 days, respectively. Table 1 reflects the comparison between the different enrolments. Maternal age differed significantly between the groups. When compared with enrolment 1 , maternal body mass index was significantly higher in enrolment 2. When compared with enrolment 1 , the number of years of formal education was significantly higher in enrolment 2. When compared with enrolment 1, mean household income was significantly lower in enrolment 2 . The lowest duration of formal education was seen in enrolment 3 , but the duration did not differ significantly from enrolments 1 and 2 (Fig. 1). When compared with enrolment 1 , the mean Edinburgh depression score was significantly lower in enrolment 2 . There were no significant differences between the three groups regarding total drinks during pregnancy, number of binge drinking episodes or mean number of cigarettes per day (Table 1). Although the gestational age at delivery declined after enrolment 1 , it did not differ significantly between the three groups (Table 2, Fig. 2). When compared with enrolment 1 , mean placental weight was significantly higher in enrolment 2 .
The same applied to the placental centile. Mean birthweight was lower in enrolment 3 , but the differences between the three groups were not significant (Table 2, Fig. 3). Birthweight $z$-scores were significantly lower in enrolment 2 compared with enrolment 1 (Table 2).

In enrolment $1,63.8 \%$ used alcohol compared with $59.0 \%$ and $54.6 \%$ in enrolments 2 and 3, respectively. The decline was not statistically significant $(p=0.058)$ (Table 3). The proportion of smokers also did not change significantly between the groups, and remained around $68.4-73.7 \%$. Use of cannabis declined in enrolment 2 but rose in enrolment 3 . The highest proportion of methamphetamine users (17.3\%) was observed in enrolment 3 . The rate of preterm deliveries increased from $15.5 \%$ in enrolment 1 to $17.5 \%$ and $24.7 \%$ in enrolments 2 and 3 , respectively, but the difference was not significant. No significant trends were found regarding the sex of the infant, miscarriages, terminations of pregnancy, stillbirths or neonatal and infant deaths.

\section{Discussion}

We found that specific information on the adverse effects of smoking and drinking during pregnancy had little effect on limiting these exposures during subsequent pregnancies. Women who had three deliveries during the prospective study over 7.5 years seemed to be more at risk for poor perinatal outcome.

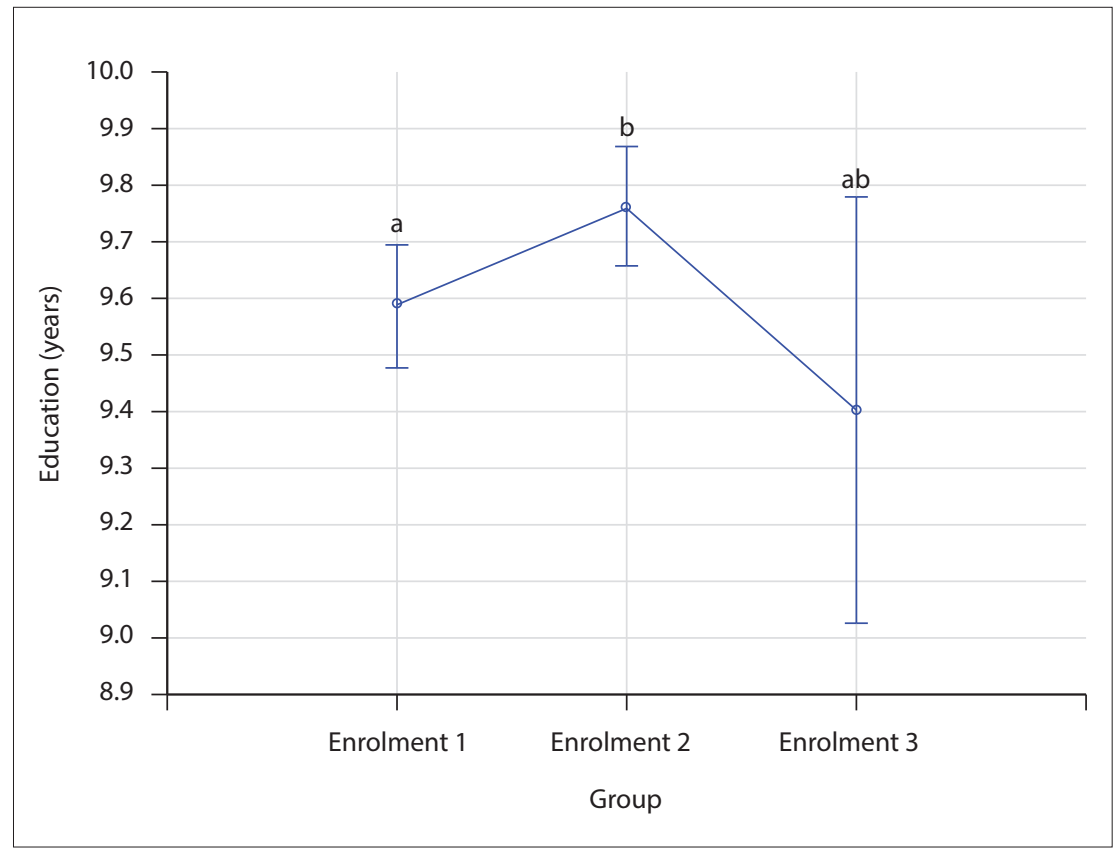

Fig. 1. Significant differences between mean years of education for the different enrolments were found $(\mathrm{F}(2,1$ 867) $=3.3138 ; \mathrm{p}=0.04)$. Whiskers denote $95 \%$ bootstrap confidence intervals, and duplicated letters above whiskers indicate absence of a significant difference. 


\section{Table 1. Comparison of different enrolments*}

\begin{tabular}{|c|c|c|c|}
\hline & Enrolment 1 & Enrolment 2 & Enrolment 3 \\
\hline Maternal age (years) & ${ }^{\mathrm{ac}} 22.9 ; 5.2 ; 22.5 ; 23.2$ & ${ }^{\mathrm{ab}} 26.2 ; 5.0 ; 25.8 ; 26.5$ & ${ }^{\text {bc }} 27.7 ; 4.4 ; 26.6 ; 29.8$ \\
\hline BMI $\left(\mathrm{kg} / \mathrm{m}^{2}\right)$ & a24.3; $5.2 ; 23.9 ; 24.7$ & a $25.2 ; 5.9 ; 24.9 ; 25.6$ & $25.0 ; 5.0 ; 23.8 ; 26.3$ \\
\hline Gravidity & ${ }^{\mathrm{ab}} 2.0 ; 1.8 ; 1.9 ; 2.1$ & ac $3.1 ; 1.2 ; 3.0 ; 3.1$ & bc $4.1 ; 1.3 ; 3.8 ; 4.3$ \\
\hline Years of formal education & a.6; $1.7 ; 9.5 ; 9.7$ & a.8; $1.6 ; 9.6 ; 9.9$ & $9.4 ; 1.7 ; 9.0 ; 7.8$ \\
\hline Household income (ZAR/month) & ${ }^{\mathrm{a}} 648 ; 500 ; 609 ; 688$ & a $822 ; 495 ; 785 ; 859$ & $706 ; 384 ; 583 ; 829$ \\
\hline Edinburgh depression score & ${ }^{\mathrm{a}} 13.8 ; 6.1 ; 13.4 ; 14.2$ & ${ }^{\mathrm{a}} 12.6 ; 5.9 ; 12.2 ; 13.1$ & $13.5 ; 6.1 ; 12.2 ; 13.1$ \\
\hline Total standard drinks during pregnancy & $22.4 ; 39.8 ; 18.9 ; 26.0$ & $22.6 ; 46.3 ; 18.9 ; 26.3$ & $28.9 ; 49.7 ; 15.8 ; 42.0$ \\
\hline Total binges during pregnancy & $2.3 ; 4.8 ; 2.1 ; 2.7$ & $2.4 ; 5.1 ; 2.0 ; 2.9$ & $3.1 ; 5.9 ; 2.0 ; 2.9$ \\
\hline Cigarettes per day & $4.3 ; 3.0 ; 4.0 ; 4.8$ & $4.6 ; 4.0 ; 4.3 ; 4.9$ & $4.3 ; 3.0 ; 3.2 ; 5.4$ \\
\hline Gestational age at enrolment (days) & ${ }^{\mathrm{a}} 147 ; 50 ; 144 ; 150$ & ${ }^{\mathrm{a}} 136 ; 51 ; 133 ; 140$ & $137 ; 56 ; 126 ; 149$ \\
\hline
\end{tabular}

Table 2. Birth outcome in different enrolments*

\begin{tabular}{|c|c|c|c|}
\hline & Enrolment 1 & Enrolment 2 & Enrolment 3 \\
\hline Gestational age at delivery (days) & $269 ; 25 ; 267 ; 271$ & $267 ; 26 ; 265 ; 268$ & $265 ; 24 ; 259 ; 271$ \\
\hline Placental weight (g) & ${ }^{\mathrm{a}} 601 ; 142 ; 591 ; 612$ & ${ }^{\mathrm{a}} 618 ; 146 ; 607 ; 628$ & $620 ; 150 ; 585654$ \\
\hline Placental weight centile & a39.1; 27.2; 37.1; 41.1 & ${ }^{\mathrm{a}} 42.9 ; 29.0 ; 40.9 ; 44.9$ & $45.5 ; 27.7 ; 38.6 ; 52.3$ \\
\hline Birthweight (g) & $2929 ; 592 ; 2890 ; 2969$ & $2966 ; 608 ; 2926 ; 3006$ & $2820 ; 668 ; 2685 ; 2955$ \\
\hline Birthweight $z$-score & ${ }^{\mathrm{a}}-0.45 ; 1.0 ;-0.52 ;-0.39$ & ${ }^{\mathrm{a}}-0.27 ; 1.0 ;-0.34 ;-0.21$ & $-0.38 ; 0.86 ;-0.61 ;-0.16$ \\
\hline
\end{tabular}

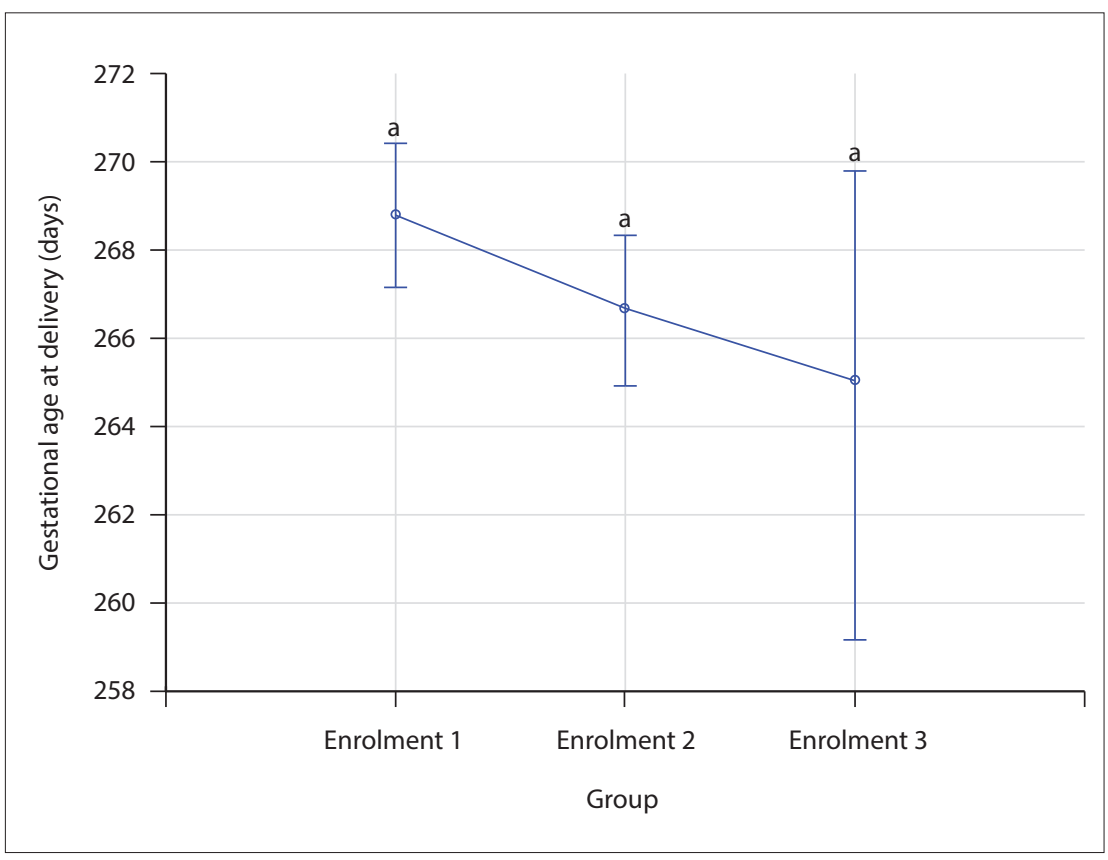

Fig. 2. No significant differences between the gestational age at delivery means for the different enrolments were found $(\mathrm{F}(2,1$ 868) $=2.1024 ; \mathrm{p}=0.12)$. Whiskers denote $95 \%$ bootstrap confidence intervals, and duplicated letters above whiskers indicate absence of a significant difference.

Low maternal income is associated with adverse fetal outcome. For example, in a study of mothers who had children diagnosed with fetal alcohol syndrome (FAS), the mean weekly income was ZAR818 per week, in comparison with ZAR2 406 per week in alcohol during pregnancy. A similar result (64.6\%) was noted in the 5046 women who were only enrolled in the study once (unpublished information, HJO; SPS), but these percentages are much higher than the $27.6 \%$ in a randomly selected control group in another study in a similar population, and even higher than the $50.8 \%$ of alcohol users in the 118 women who had children with FAS. ${ }^{[8]}$ In an earlier study, May et al. ${ }^{\left[{ }^{[9]}\right.}$ found that the prevalence of alcohol use was $24.2 \%$ in their control group.

We found that the prevalence rate of smokers ranged between $68.4 \%$ and $73.3 \%$ for the three enrolment groups (Table 3), which is similar to the $66.4 \%$ of women who were enrolled in the study only once (unpublished data, HJO; SPS). Our prevalence rate is similar to the $75 \%$ of women who had children diagnosed with FAS found by May et al. ${ }^{[8]}$ and much higher than the $32.7 \%$ of women in their control group. ${ }^{[8]}$ In another study, the prevalence rate of smoking in the control group of 133 women was $35.6 \% .^{\left[{ }^{[9]}\right.}$

In the multisite SPS, which comprised six different population groups, ${ }^{[7]}$ we found that $52.2 \%$ of women used alcohol during pregnancy and $47.9 \%$ smoked.

Our finding that $9.7-15.1 \%$ of women who had more than one delivery during the study period smoked cannabis during 
Table 3. Information on smoking, drinking, drug use and outcome of pregnancy*

\begin{tabular}{|c|c|c|c|c|c|}
\hline & $\begin{array}{l}\text { Enrolment } 1 \\
(N=889)^{\dagger}\end{array}$ & $\begin{array}{l}\text { Enrolment } 2 \\
(N=888)^{\dagger}\end{array}$ & $\begin{array}{l}\text { Enrolment } 3 \\
(N=77)^{\dagger}\end{array}$ & $\chi^{2}$ & $p$-value \\
\hline Drinkers & $567(63.8)$ & $524(59.0)$ & $42(54.6)$ & 5.7 & 0.058 \\
\hline Smokers & $652(73.7)$ & $643(72.3)$ & $52(68.4)$ & 1.16 & $>0.05$ \\
\hline Cannabis & $129(15.1)$ & $85(9.7)$ & $9(12.0)$ & 11.53 & $<0.005$ \\
\hline Methamphetamine & $86(10.1)$ & $58(6.6)$ & $13(17.3)$ & 12.71 & $<0.005$ \\
\hline Preterm deliveries & $139(15.5)$ & $157(17.5)$ & 19 (24.7) & 4.5 & $>0.05$ \\
\hline Female infants & $425(48.0)$ & $424(48.0)$ & $41(53.3)$ & 0.05 & $>0.05$ \\
\hline Miscarriages & $11(1.23)$ & $12(1.34)$ & $1(1.30)$ & 0.04 & $>0.05$ \\
\hline Terminations of pregnancy & $2(0.23)$ & $2(0.23)$ & 0 & 0.34 & $>0.05$ \\
\hline Stillbirths & $21(2.38)$ & $12(1.36)$ & $3(3.95)$ & 3.81 & $>0.05$ \\
\hline Early neonatal deaths & $5(0.58)$ & $6(0.69)$ & $1(1.37)$ & 0.53 & $>0.05$ \\
\hline Late neonatal deaths & 0 & $2(0.23)$ & 0 & 2.92 & $>0.05$ \\
\hline Infant deaths in 1st year & $14(1.63)$ & $6(0.7)$ & $1(1.39)$ & 3.41 & $>0.05$ \\
\hline
\end{tabular}

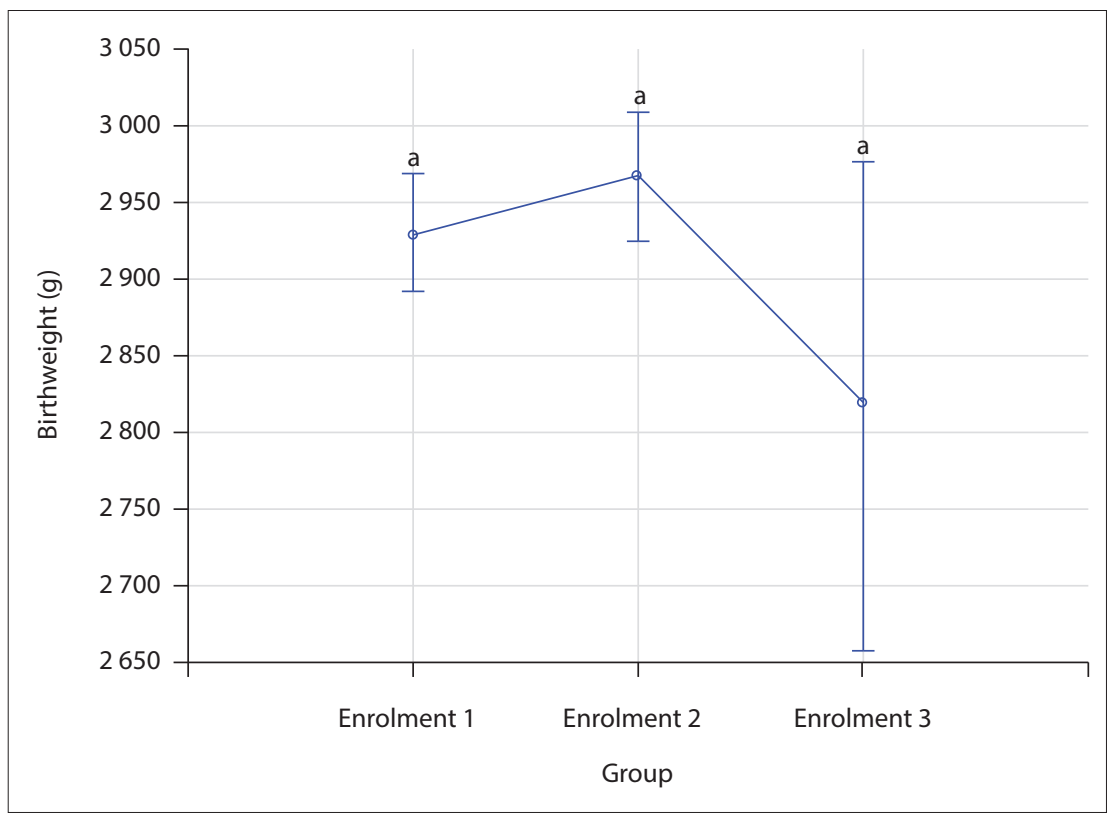

Fig. 3. No significant differences between the birthweight means for the different enrolments were found $(\mathrm{F}(2,1$ 868) $=2.2486 ; \mathrm{p}=0.09)$. Whiskers denote $95 \%$ bootstrap confidence intervals, and duplicated letters above whiskers indicate absence of a significant difference.

pregnancy was not much different from the cannabis use rate of $9.9 \%$ in women enrolled in the study only once (unpublished data, HJO; SPS), and similar to the prevalence rate of $9 \%$ we found in the cohort of 1679 women in whom maternal serum alpha-fetoprotein (MSAFP) levels were determined. ${ }^{[10]}$

The same applies to the $6.6 \%$ of methamphetamine users found in enrolment 2 (Table 3) compared with $5 \%$ in women who were in the study once (unpublished data, HJO; SPS) or compared with $5 \%$ in women in whom MSAFP was measured. ${ }^{[10]}$ However, the highest rate of methamphetamine use $(17.3 \%)$ was found in the group of 77 women who enrolled for their third pregnancy. The and that modification of this interval may be unlikely to have a major effect on low birthweight. ${ }^{[12]}$ This finding is supported by a more recent finding of a study using data on 1416 women in the Scandinavian smallfor-gestational-age study that the association between a short inter-pregnancy interval and low birthweight may reflect confounding by socioeconomic and other unmeasured factors. ${ }^{[13]}$

As some pregnant women have little knowledge of the consequences of tobacco use, ${ }^{[14]}$ several different programmes are available to facilitate quitting. These programmes include the implementation of system-wide complex healthcare intervention, ${ }^{[15]}$ incentives, ${ }^{[16]}$ self-help and clinical support, ${ }^{[17]}$ and integrated brief intervention. ${ }^{[18]}$ Schneider et al. ${ }^{[19]} \operatorname{did}$ a systematic review of 19 identified studies and came to the conclusion that the rate of quitters varied from $4.0 \%$ to $69.7 \%$ for population-based studies and from $26.5 \%$ to $47.0 \%$ for clinical-based studies. Smoking cessation programmes during pregnancy seem to be cost-effective for preventing low birthweight if they cost $<$ USD80 and they have achieved success rates of at least $18 \%{ }^{[20]}$ However, a Cochrane review found that there is insufficient evidence to show whether motivational intervention helps people to stop smoking compared with no intervention, as an addition to other types of behavioural support for smoking cessation, or compared with other types of behavioural support for smoking cessation. ${ }^{[21]}$

When compared with smoking, less information was available on intervention programmes to stop or reduce drinking during pregnancy. The C-BIAP (Computerized Brief Intervention for Alcohol use in 
Pregnancy) seems to be feasible and acceptable to pregnant women who do not report current drinking, and cognitive behavioural intervention seems to be helpful. ${ }^{[22]}$ This approach may be useful in clinics where staff time is limited. ${ }^{[23]}$ More recently, case management was evaluated in a population similar to the index study. ${ }^{[24]}$ It was demonstrated to be successful for women with high-risk drinking behaviour while pregnant. It is important to remember that more social support to quit smoking is associated with spontaneous alcohol abstinence. ${ }^{[25]}$

\section{Conclusions}

Short inter-pregnancy intervals, as suggested by three enrolments in 7.5 years, are associated with preterm labour and growth restriction, and are therefore indicative of the probable role played by confounders such as poor socioeconomic conditions and cannabis and methamphetamine exposure during pregnancy. We have demonstrated that detailed information on the adverse effects of smoking and drinking during pregnancy was not effective in the population studied. Other methods to reduce harmful exposure should therefore be investigated.

\section{Declaration. None.}

Acknowledgements. Personnel of the Safe Passage Study for their hard work. Author contributions. HJO: principal investigator of the study, designed the study, wrote the draft manuscript, edited all revised manuscripts. LTB: extracted the required clinical information from the data base, designed the tables and figures, provided information to calculate the $z$-scores, quality control of data, contributed to the writing and editing, checked the data at the end, edited all revised manuscripts. DGN: advised on and performed the statistical analyses, wrote the methods section on statistical analyses, edited the final manuscript. EC, MdG, MP, CdP: were actively involved in the recruitment, assessments and follow-up of participants, advised on the planning of the study, contributed to the methods section, read and edited the final manuscript. CAG: project manager, co-ordinated the study, was actively involved in the recruitment, assessments and follow-up of participants, contributed to the methods and discussion sections, read and edited the final manuscript.

Funding. The study was funded by the National Institute on Alcohol Abuse and Alcoholism, the Eunice Kennedy Shriver National Institute of Child Health and Human Development, and the National Institute on Deafness and Other Communication Disorders: U01 HD055154, U01 HD045935, U01 HD055155, U01 HD04599 and U01 AA016501.

Conflicts of interest. None.
1. Lange S, Probst C, Gmel G, Rehm J, Burd L, Popova S. Global prevalence of fetal alcohol spectrum disorder among children and youth: A systematic review and meta-analysis. Obstet Gynecol Sury 2018;73(4):189-191. https://doi.org/10.1097/01.ogx.0000532194.88210.00

2. Pineles BL, Hsu S, Park E, Samet JM. Systematic review and meta-analyses of perinatal death and Pineles BL, Hsu S, Park E, Samet JM. Systematic review and meta-analyses of perinatal death and
maternal exposure to tobacco smoke during pregnancy. Am J Epidemiol 2016;184(2):87-97. https://doi. maternal exposure to to
$\mathrm{org} / 10.1093 / \mathrm{aje} / \mathrm{kwv} 301$

3. Anderson TM, Lavista Ferres JM, You Ren S, et al. Maternal smoking before and during pregnancy and Anderson TM, Lavista Ferres JM, You Ren S, et al. Maternal smoking before and during pregnancy and
the risk of sudden unexpected infant death. Pediatrics 2019;143(4):e20183325. https://doi.org/10.1542 the risk of sudde
peds.2018-3325

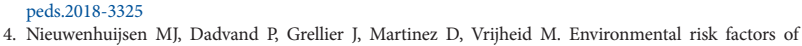

Nieuwenhuijsen MJ, Dadvand P, Grellier J, Martinez D, Vrijheid M. Environmental risk factors of
pregnancy outcomes: A summary of recent meta-analyses of epidemiological studies. Environ Health 2013;12:6. https://doi.org/10.1186/1476-069X-12-6

5. Dejong K, Olyaei A, Lo JO. Alcohol use in pregnancy. Clin Obstet Gynecol 2019;62(1):142-155. https:// doi.org/10.1097/grf.0000000000000414

6. Nykjaer C, Alwan NA, Greenwood DC, et al. Maternal alcohol intake prior to and during pregnancy and risk of adverse birth outcomes: Evidence from a British cohort. J Epidemiol Community Health 2014;68(6):542-549. https://doi.org/10.1136/jech-2013-202934

7. Dukes KA, Burd L, Elliott AJ, et al. The Safe Passage Study: Design, methods, recruitment, and follow-up approach. Paediatr Perinat Epidemiol 2014;28(5):455-465. https://doi.org/10.1111/ppe.12136

8. May PA, de Vries MM, Marais AS, et al. Replication of high fetal alcohol spectrum disorders prevalence rates, child characteristics, and maternal risk factors in a second sample of rural communities in South Africa. Int J Environ Res Public Health 2017;14(5):552. https://doi.org/10.3390/ijerph14050522

9. May PA, Gossage JP, Marais AS, et al. The epidemiology of fetal alcohol syndrome and partial FAS in a South African community. Drug Alcohol Depend 2007;88(2-3):259-271. https://doi.org/10.1016/j. drugalcdep.2006.11.007

10. Odendaal HJ, Geerts L, Nel DG, Brink LT, Hitchcock E, Groenewald CA. Effects of alcohol, cigarettes methamphetamine and marijuana exposure during pregnancy on maternal serum alpha-fetoprotein levels at $20-24$ weeks'gestation. I Pediatr Neonatal Care 2018:8(1). https://doi.org/10.15406/ jpnc.2018.08.00314

11. Kramer MS. Determinants of low birth weight: Methodological assessment and meta-analysis. Bull World Health Organ 1987;65(5):663-737.

12. Klebanoff MA. Short interpregnancy interval and the risk of low birthweight. Am J Public Health 1988;78(6):667-670. https://doi.org/10.2105/ajph.78.6.667

13. Liauw J, Jacobsen GW, Larose TL, Hutcheon JA. Short interpregnancy interval and poor fetal growth: Evaluating the role of pregnancy intention. Paediatr Perinat Epidemiol 2019;33(1):O73-O85. https://doi.
E Evaluating the role of pre
$\mathrm{org} / 10.1111 / \mathrm{ppe} .12506$

org/10.1111/ppe.12506
14. Bertani AL, Garcia T, Tanni SE, Godoy I. Preventing smoking during pregnancy: The importance Bertani AL, Garcia T, Tanni SE, Godoy I. Preventing smoking during pregnancy: The importance
of maternal knowledge of the health hazards and of the treatment options available. J Bras Pneumol of maternal knowledge of the health hazards and of the treatment options

15. Bell R, Glinianaia SV, van der Waal Z, et al. Evaluation of a complex healthcare intervention to increase smoking cessation in pregnant women: Interrupted time series analysis with economic evaluation. Tob Control 2018;27(1):90-98. https://doi.org/10.1136/tobaccocontrol-2016-053476

16. Notley C, Gentry S, Livingstone-Banks J, Bauld L, Perera R, Hartmann-Boyce J. Incentives for smoking cessation. Cochrane Database Syst Rev 2019, Issue 7. Art. No.: CD004307. https://do org/10.1002/14651858.cd004307.pub6

17. Petersen L, Handel J, Kotch J, Podeworny T, Rosen A. Smoking reduction during pregnancy by a program of self-help and clinical support. Obstet Gynecol 1992;79(6):924-930

18. Bowden JA, Oag DA, Smith KL, Miller CL. An integrated brief intervention to address smoking in pregnancy. Acta Obstet Gynecol Scand 2010;89(4):496-504. https://doi.org/10.3109/0001634100371386

9. Schneider S, Huy C, Schütz J, Diehl K. Smoking cessation during pregnancy: A systematic literature review. Drug Alcohol Rev 2010;29(1):81-90. https://doi.org/10.1111/j.1465-3362.2009.00098.x

20. Hueston WJ, Mainous AG, Farrell JB. A cost-benefit analysis of smoking cessation programs during the first trimester of pregnancy for the prevention of low birthweight. J Fam Pract 1994;39(4):353-357.

21. Lindson N, Thompson TP, Ferrey A, Lambert JD, Aveyard P. Motivational interviewing fo smoking cessation. Cochrane Database Syst Rev 2019, Issue 7. Art. No.: CD006936. https://doi org/10.1002/14651858.cd006936.pub4

22. Pollick SA, Beatty JR, Sokol RJ, et al. Acceptability of a computerized brief intervention for alcohol among abstinent but at-risk pregnant women. Subst Abuse 2015;36(1):13-20. https://doi.org/10.1080/08897077 .2013 .857631

23. Reynolds KD, Coombs DW, Lowe JB, Peterson PL, Gayoso E. Evaluation of a self-help program to reduce alcohol consumption among pregnant women. Int J Addict 1995;30(4):427-443. https://doi.
org/10.3109/10826089509048735

24. De Vries MM, Joubert B, Cloete M, et al. Indicated prevention of fetal alcohol spectrum disorders in De Vries MM, Joubert B, Cloete M, et al. Indicated prevention of fetal alcohol spectrum disorders in
South Africa: Effectiveness of case management. Int J Environ Res Public Health 2015;13(1):1-14. https://

25. Ockene JK, Ma Y, Zapka JG, Pbert LA, Valentine Goins K, Stoddard AM. Spontaneous cessation of Ockene JK, Ma Y, Zapka JG, Pbert LA, Valentine Goins K, Stoddard AM. Spontaneous cessation of
smoking and alcohol use among low-income pregnant women. Am J Prev Med 2002;23(3):150-159. https://doi.org/10.1016/s0749-3797(02)00492-0

Accepted 12 August 2020 